\title{
A response from the Chairman
}

\author{
Peter Fallon
}

Our Report into the Personality Disorder Unit (Fallon et al, 1999) is the unanimous view of the committee. The Editor of the Psychiatric Bulletin initially invited Professor Bluglass to reply to Dr Maden's critique which appears in this Bulletin no doubt because he is even more critical of Professor Bluglass than he is of the report itself. In these circumstances after consulting with my colleagues it seems more appropriate that, as Chairman of the Committee, I should put pen to paper.

In addition to Maden's critique (see pages 455-457, this issue), Professor Gunn has commented elsewhere (Gunn, 1999). Both have repeated the tabloid guess that the Inquiry cost $£ 7.5$ million. An enquiry of our secretariat would have revealed that at the time this extravagant claim was made the cost was £2.5 million with one or two outstanding accounts to be received. To keep matters in perspective, during the two years from appointment of the committee to publication of the report, the management costs of the patients in Lawrence Ward alone, at an annual cost of $£ 106000$ per patient, amounted to over \&4 million.

The root cause of many of Ashworth's problems with the Personality Disorder Unit lay in the implementation of the Blom-Cooper Report's recommendations (Blom-Cooper et al, 1992). Even the College in its comments on our report misses the point that it was not Blom-Cooper's fault that liberalisation was applied across the board. His report was concerned with ill-treatment of the mentally ill. It was not concerned with people with personality disorders. The decision was a ministerial one, but in reality nobody, it seemed, had the sense to differentiate between the different needs of the two groups.

A fuller reading of our report would also have disclosed our determination not to blame individuals who were doing their best in a system that was flawed. We bore this firmly in our minds in drawing our conclusions. Those who assume important positions of leadership do have to be accountable for their actions and performance.

In asserting we exceeded our terms of reference, Dr Maden fails to bear in mind our second term of reference. To report on that term it was essential to:

(a) determine the different security requirements of the mentally ill and the person- ality disordered and the nature of the clinical care and management of people with personality disorders;

(b) consider the nature of personality disorders from the point of view of treatability. management and risk of causing serious harm to others.

He also ignores that in announcing our appointment in the House of Commons the then Secretary of State said that our committee would wish to follow up wider questions in considering the issues which led to Ashworth's problems. Dr Maden did not know that the present Secretary of State, the Rt Hon. Frank Dobson MP, after listening to our preliminary views before writing the report, added his encouragement to the Committee to examine the policies, clinical care and procedures governing persons suffering from personality disorder with a view to formulating positive recommendations for action to ensure their proper management in the future.

Dr Maden states that we were an inappropriate body to consider the problems that we believed it was necessary to face in order to give sensible advice. From the outset the lack of agreement among psychiatrists, psychologists, nurses and others about the diagnosis, categorisation, treatability and appropriate management of offenders with severe personality disorder was evident. The past history of failure to resolve these matters in a realistic and pragmatic way is described in Volume I. We took appropriate expert evidence now published in Volume II (Fallon et al, 1999). That evidence speaks for itself and is the foundation of many of the conclusions found in Volume I which contains the first positive advice in an official report on the management of severe personality disordered offenders since Butler. We had of course hoped that the Royal College would guide us, but regrettably the valuable paper that has now been published on severe personality disorder was not produced in time to assist us. We are pleased to find that many of its conclusions are similar to our own - but we are not surprised. Volume II contains the evidence of five of the eight members of the reporting committee.

Despite Dr Maden's various attacks it is interesting to see that the College's official comments on our report which are published in this issue of the Psychiatric Bulletin (see pages 452-454) are poles apart from those of Dr 
Maden. In making the following comments the College appears to share many of our conclusions:

(a) the essential villain was the system;

(b) the special hospitals are extremely diffcult to manage in their existing form being too large and complex especially when the very different needs of the mentally ill and the personality disordered have to be met in the same institution;

(c) such hospitals should not contain more than 200-250 beds;

(d) hospitals of that size should be integrated with the National Health Service in general and forensic mental health services and medium secure units to facilitate transfer of patients between different levels of security:

(e) good forensic psychiatrists are deterred from working in the special hospitals for a number of deep seated problems including the isolation of the hospitals geographically, professionally and socially;

(f) the tarnished reputation of the hospitals;

(g) the mentally ill and the personality disordered (even those prone to overt illness of various kinds) require different regimes and need to be kept separate;

(h) strong agreement that hospital orders should no longer be available to personality disordered offenders;

(i) the presence in special hospitals of men unwilling to be treated and probably untreatable who have to be retained indefinitely is a recipe for disaster and one of the cardinal causes in the problems in Personality Disorder Unit;

(j) the term 'psychopathic disorder' should be removed from mental health law.

Of our 58 recommendations the only one not immediately accepted was that to close Ashworth at the earliest opportunity. It was not our headline recommendation as Dr Maden calls it. It was headlined in the press because of its newsworthiness. We knew well in advance of writing most of the report that the Secretary of State was not minded to close the hospital. We gave much thought to this proposal but we were all convinced that Ashworth's appalling history, the recent events, the continued failure of management and all the evidence we had heard, led only in that direction. Even the then Chairman of Ashworth, Mr Paul Lever, was of the view that the hospital was not recoverable in its present form.

We also considered this recommendation to be consistent with the recommendations we made concerning the future in Part 7 of Volume $I$. According to Dr Maden our conclusion was "unargued and half-baked". According to Professor Gunn we offered very little practical advice but "simply despaired, told the government to shut the place down and walked away". Anyone who cares to read Part 7 will appreciate those comments are unjustified and without foundation. In 7.3.22 we say that Ashworth could only close after appropriate regional networks and new services are in place. A modern forensic psychiatric service does not need three large high security hospitals.

Of course there is room for debate, discussion and the holding of different views. In its comments the College does not agree with our view about closure, but it follows our reasoning and acknowledges in particular that the special hospitals are too big and extremely difficult to manage in their present form for similar reasons to those we give.

We proposed a new forensic network. It was not modelled at all on the medium secure services although they are a vital and integral part of the network. The object is to put forensic psychiatry in the same developmental mode as other parts of medicine where seamless integrated care is highly prized and shown to be successful.

We believe that now is the time to grasp the opportunity to change the face of forensic psychiatry in the UK. There is a better way which most of the clinical and managerial community see clearly as we discovered when questioning our expert witnesses about this 'new world' concept. We reflect that better way in our proposals for change. A despairing defence of the status quo as seen in Professor Gunn's (1999) British Medical Journal paper and in Dr Maden's critique will lead nowhere except to another inquiry. The time is ripe for decisive leadership and change and in this regard we are most encouraged by the response of the Royal College and the animated discussions about change and progress we hear reports of up and down the country.

Dr Maden is particularly offensive in assaulting the professional integrity of Professor Bluglass; in suggesting that he would try to influence his colleagues; in inferring that three other independently minded members could be so influenced; in making accusations of bias to be found lurking in the report, and in accusing the committee of naivety believing the 'treatable' and the 'untreatable' are as distinct as sheep and goats. He should have awaited Volume II before penning such extravagant insults.

We refer to Professor Bluglass's (1992) editorial in the British Medical Journal on page 16 of our report where we say that he "recommended replacing the hospitals with new, smaller local high security units linked to local regional secure units". Reference to the Pinochet case implies 


\section{REVIEW ARTICLES}

that he failed to disclose an interest. Not only was this editorial well known, but he reminded the Department of Health of it before accepting appointment to the committee. They had no doubt about his integrity nor would any levelheaded person who knows him have any doubt. To imply that he would ever contemplate trying to 'highjack' his colleagues grossly insults his integrity and international reputation; to imply that his colleagues would allow themselves to be hijacked equally insults their integrity and reputations.

Maden goes on to make the absurd generalisation that those who are retired, even recently retired, are no longer competent to serve on judicial inquiries, because they are out of touch with good professional practice and standards. Similar arguments would apply to two other members of our committee. If applied generally many others would be unable to use their long experience and knowledge and give their services after retiring from their original professional appointment such as many Mental Health Tribunal members, locum doctors, members of inspectorates, additional judges, expert witnesses and even Presidents of Royal Colleges.

He also demonstrates a total misunderstanding of the need for independence of judicial tribunals. The notion that the College should provide a validated list of suitable appointees to serve on such inquiries raises important questions about the independence of government and the bias that might well be introduced by including in such a list only people of a particular outlook or those who hold view of which the College, or certain members approve. The medical member of the inquiry is not a representative of the College. It is essential that the government appoints anyone they consider appropriate, whether from a legal, medical or other background.

Dr Maden tells us that many aspects of our report will be quickly forgotten, a mischievous comment, since only one of our recommendations has not been adopted. He may want to forget it but the Secretary of State has a different view. When introducing the report to the House of Commons, having referred to reports we considered but which had been concealed and remained unimplemented he said: "I am determined that this report will not suffer the same fate".

We stand by our unanimous report. The future will judge its longevity, and the role it may have played in stimulating change in this important branch of medicine.

\section{References}

BLOM-COOPER, L., BROWN, M., DOLAN, R., et al (1992) Report of the Committee of Inquiry into Complaints About Ashworth Special Hospital. Cm 2028-I-II. London: HMSO.

BLuglass, R. (1992) The spectal hospitals should be closed. British Medical Joumal, S06, 323-324.

FALION, P. BLUGLASS, R. EDWARDS, B., et al (1999) Report of the Committee into the Personality Disorder Unit. Ashworth Special Hospital. Cm 4194-II. London: The Stationery Office.

GunN, J. (1999) Ashworth revisited. British Medical Journal, 818, 271.

His Honour Peter Fallon QC. Chairman, Committee of Inquiry into Personality Disorder Unit, Ashworth Special Hospital, c/o The Law Courts, Small Street, Bristol BS1 IDA 